\title{
Measurement and Evaluation Model of Shipbuilding Production Efficiency
}

\author{
Shi Guofu ${ }^{1}$, Liu Xiaobing ${ }^{1}$, Xu Yizhuang ${ }^{2}$, Yao Nailong ${ }^{3}$ \\ ${ }^{1}$ School of Management and Economics, Dalian University of Technology, Dalian, China \\ ${ }^{2}$ Department of Audit, Dalian Shipbuilding Heavy Industry Co. Ltd., Dalian, China \\ ${ }^{3}$ No.1 Dock Assembly Department, Dalian Shipbuilding Heavy Industry Co. Ltd., Dalian, China \\ Email address: \\ 1272734025@qq.com (Shi Guofu)
}

\section{To cite this article:}

Shi Guofu, Liu Xiaobing, Xu Yizhuang, Yao Nailong. Measurement and Evaluation Model of Shipbuilding Production Efficiency. International Journal of Economic Behavior and Organization. Vol. 5, No. 6, 2017, pp. 149-161. doi: 10.11648/j.ijebo.20170506.15

Received: November 5, 2017; Accepted: November 23, 2017; Published: December 28, 2017

\begin{abstract}
How to evaluate the level of the production efficiency and the changes of productivity is important for the shipyard improvement and survive. The efficiency of the shipyard is comprehensively affected by the managing, technical activities and product mix. The causes of inefficiency are hidden somewhere inside of the production system. From these points of view, the Efficiency Measurement Model of the general assembly shipbuilding production is developed based on the production system breakdown structures. By this model, the organization efficiency, activity efficiency and product efficiency can be measured by corresponding efficiency indicators reflecting the efficiency level or the productivity changes all over the production system. The empirical application shows this model is a suitable approach to analyze the efficiency of the general assembly shipbuilding production system in finding the inner causes of inefficiency and the proper measures to improve the production efficiency.
\end{abstract}

Keywords: Efficiency, Productivity, Shipbuilding, Assembly, DEA

\section{Introduction}

Through the rapid development of the last several decades, especially the fantastic development of China's shipbuilding industry in the recent 20 years, the world shipbuilding industry is largely suffered by severe overcapacity and the rising shipbuilding cost currently. How to make the shipbuilding enterprises survive and how to develop the shipbuilding industry at this tough time are the urgent issues to be addressed for the shipbuilding industry and the main shipbuilding countries, especially China [1].

Production efficiency is one of the core competitiveness indexes for the enterprises, which shows not only the capacity utilization but also the production resources utilization. Improving the production efficiency is one of the most important means to get through the crisis experienced by the current shipbuilding industry. How to evaluate the production efficiency and how to find the internal causes of inefficiency are the first two steps for the shipbuilding industry to find ways to improve the production efficiency [2] [3].
Shipbuilding is a complex project with multiple inputs and outputs. Although the efficiency indexes currently used in the shipbuilding industry such as the working hour per $C G T$ (Corrected Gross Tonnage), the output of per production facilities area unit etc. can roughly compare the production efficiency level of the different shipyards [4], but they can merely show the utilization of some of the production factors, rather than fully showing the roles of various production, technique and management activities on the production efficiency. Therefore, it is insufficient to apply these indexes to show the production efficiency levels of different enterprises and find the internal cause of inefficiency of general-assembly shipbuilding.

\section{Literature Review}

Efficiency is an ever-lasting research subject in the economic field. Various attempts and reforms have been carried out in China's shipbuilding industry in recent years targeting at improving the production efficiency. In summary, the studies on shipbuilding production efficiency are roughly 
focused on two aspects: one is on the approaches of improving efficiency and the other is on the evaluation methods of production efficiency

(1) Studies on the approaches

Since the 1990s, a series of reforms and innovations of shipbuilding activities from concept to action has been made for the purpose of improving the shipbuilding production efficiency. Chen Qiang (2001) proposes the conception of setting up a "central shipbuilding mode" and applied in SWS, draws the conclusion that the general-assembly shipbuilding mode (GAS) [5]. Zhang Minghua (2005) discusses how to carry out the lean production mode to the shipbuilding enterprises to improve the production efficiency by applying the methodology of value engineering, and applied in NACKS with a great efficiency improvement [4]. Yu Fengping (2010) proposes a GAS model based on the specification of work theory and the application of the system analysis methodology and applied in DSIC with a great productivity improvement [6].

(2) Studies on the measuring methodology

In terms of measuring methodology of production efficiency, scholars apply the SFA (Stochastic Frontier Analysis) and DEA (Data envelopment analysis) measuring methods to make numerous empirical research on the shipbuilding production efficiency from different perspectives [7-10]. David Blazek and Robin C. Sickles (2010) applied the method of stochastic frontier analysis, established a new analytical model framework and drew the conclusion that technological innovation is the main driving factor of productivity growth [12]. It also becomes popular to measure the efficiency of shipbuilding by DEA method recently in China. Most of these studies are trying to prove DEA is a suitable tool to analyze the performance of shipbuilding industry, such as Zhang Yunhua (2007) [4], (Zhang hao and $\mathrm{Xu}$ Xuanguo 2007) [13], (Yue Na 2011) [14], (Chen Yong et al. 2011) [15], (Zhang Li et al. 2011) [16], (Ge Yongda et al. 2012) [17], (JUNG-SUN LEE 2013) [18], (Jing Wei and Jing Xuehuai 2014) [19], (Jaehun Park et al. 2014) [20]'s studies.

Scholars also tried to evaluate the shipbuilding efficiency in other ways. Tao Yonghong et al. (2013) [21] analyze and evaluate the shipbuilding efficiency by solving the Sto NED model via the software programming of gams 23.7. Zhou Chengyin et al. (2014) [22] propose the concept of China's Shipbuilding Development Index by using a scientific evaluation method and the indexed expression form. Qu Yuge (2014) [23] measures and calculates the basic features of the temporal evolution and space distribution of the total factor productivity of the shipbuilding industries by applying the Malquist index method.

(3) Limitation of existing studies

As discussed above, it is known that the GAS mode has been widely accepted and applied in China. GSA played a major role in the development of China's shipbuilding industry. But most of the studies on the measurement methods of the GAS production efficiency are still limited on measuring the overall efficiency from a global perspective, few of them is focus on the contributions of the production, technologies and management activities to the production efficiency.

The production efficiency of GAS is the combined effect of all the production, technology and management activities. In the purples to find the internal causes of inefficiency and the proper way to improve the efficiency, it is necessary to develop an efficiency measuring model which is capable of reflecting the efficiency of each aspect of GAS and the roles of production, technology and management activity on the production efficiency.

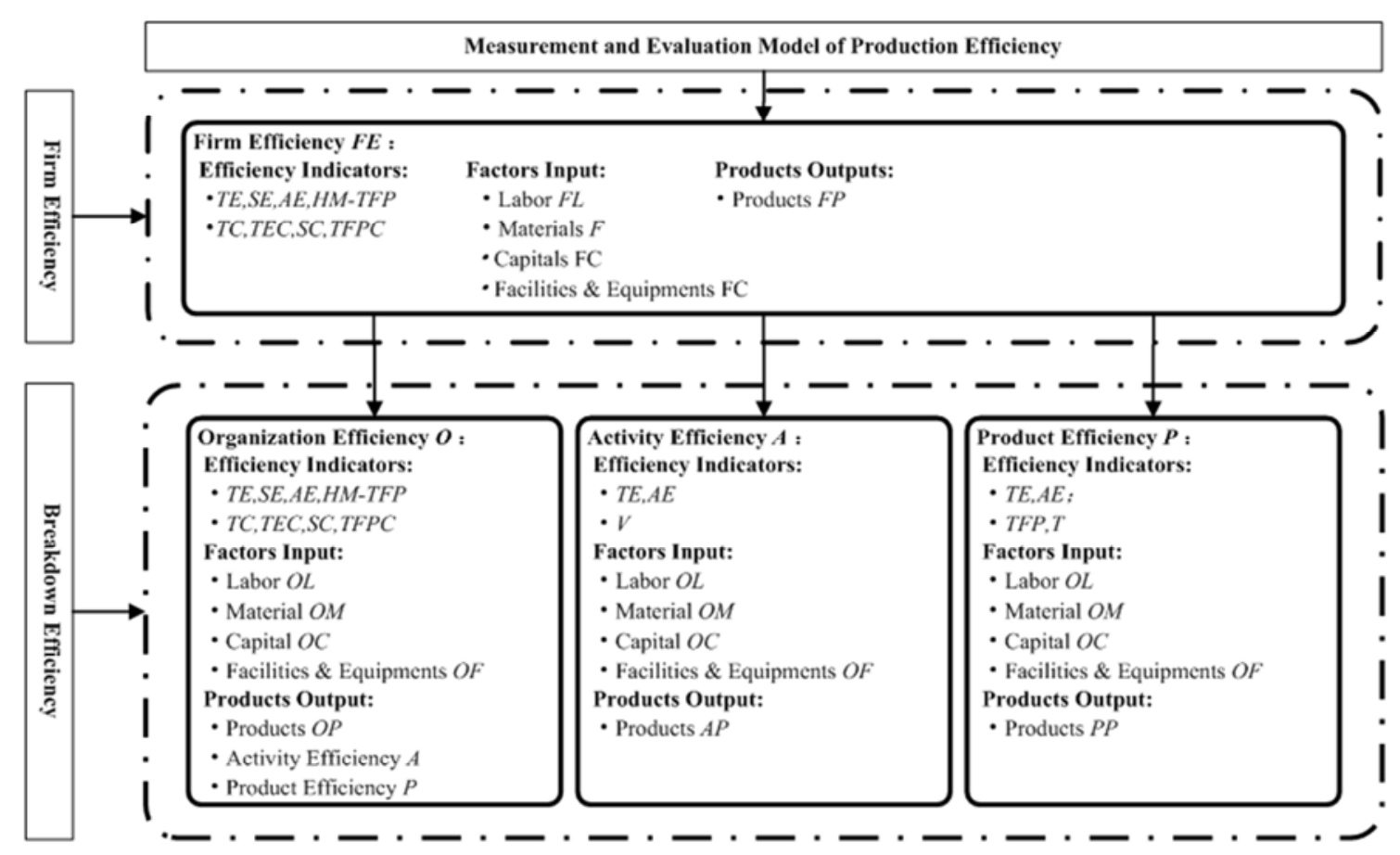

Figure 1. Measurement and Evaluation Model of Production Efficiency. 


\section{A Conceptual Framework}

This shipbuilding efficiency evaluation model is going to be developed by four steps.

(1) Specify the production system

(2) Select and design the suitable methodology and indicators

(3) Select the input and output variables data

(4) Calculate and analyze the results

In this case, the efficiency of the GAS is going to be decomposed into two parts, one is the firm efficiency, and the other is the breakdown efficiency. A shipbuilding production system breakdown structure will be constructed, and an efficiency breakdown structure will be obtained accordingly. A set of corresponding methodology will be designed, and finally the efficiency measurement model of GAS could be integrated. The conceptual framework of this model is shown in Figure 1.

\section{Efficiency Breakdown Structure}

\subsection{Production System of GAS}

The production efficiency of GAS can be defined as the ratio of the actual outputs of the assembly shipbuilding production system to its optimal outputs; it means the utilization of the production factors input by the whole shipbuilding production system. Production efficiency must correspond with a certain production system. The GAS production system can be defined in its broad or narrow sense. The broad GAS production system is composed of the shipyard and its supporting enterprises, and the narrow one only refers to the shipyard. The narrow GAS can be regard as a special case of the broad one if the materials, equipments, intermediate products and services provided by the supporting enterprises are regarded as the factors input in which the supporting enterprise's production efficiency is already included.

\subsection{Production System Breakdown Structure}

(1) Purposes and principles
The GAS production system is complicated and big. When the GAS production system is inefficiency, it is impossible to find the inner causes by the system efficiency result measured as a whole. If the GAS production system can be divided into a number of small production systems, and the efficiency of these small systems can be measured, some inefficiency small systems are destined to be found and the causes of inefficiency must be in them. It is much easier to find the causes of inefficiency in a small production system than in a big one. The efficiency of these divided production systems can be defined as the internal efficiency of the GAS. In order to have a comprehensive view of the internal efficiency of the GAS, a production system break down structure is needed. The breakdown structure of GAS shall follow two basic principles:

1) Each sub-production system shall have a clear inputs factors and products outputs interface.

2) The role of influence factors on the production efficiency can be showed among the similar sub-production systems.

The breakdown structure system of the GAS can be expressed by a mathematical set. Supposing that $S$ is a broad GAS system and $S_{n}$ is the n-th production sub-system, in the way, the production system and sub- production systems of a broad GAS can be expressed by formula 1 and 2 :

$$
\begin{gathered}
S=\left\{s_{1}, s_{2}, \cdots, S_{n}\right\} \\
S_{1}=\left\{s_{11}, s_{12}, \cdots, S_{1 n}\right\}
\end{gathered}
$$

Studies show that the management activities, production technique and the product mix are three most important influence factors to the production efficiency. Normally, the production management is the jobs of production organizations, the production technologies are applied in the production activities, and the shipbuilding products are classified in types. In view of this, the GAS production breakdown system is classified into three types by the production organizations, production activities and product types.

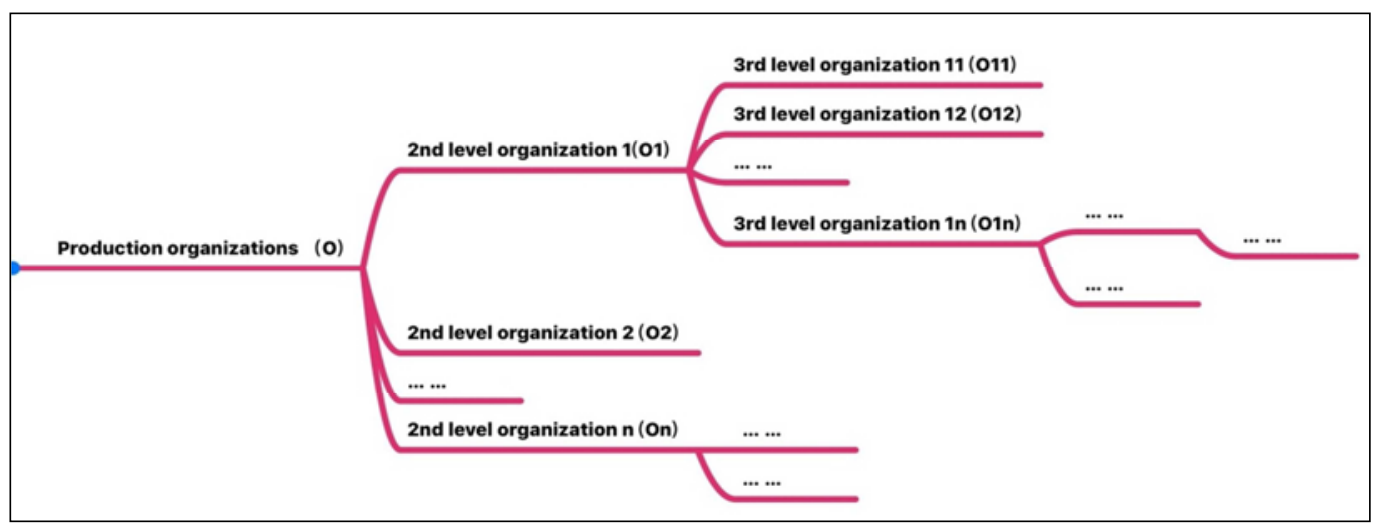

(a) 


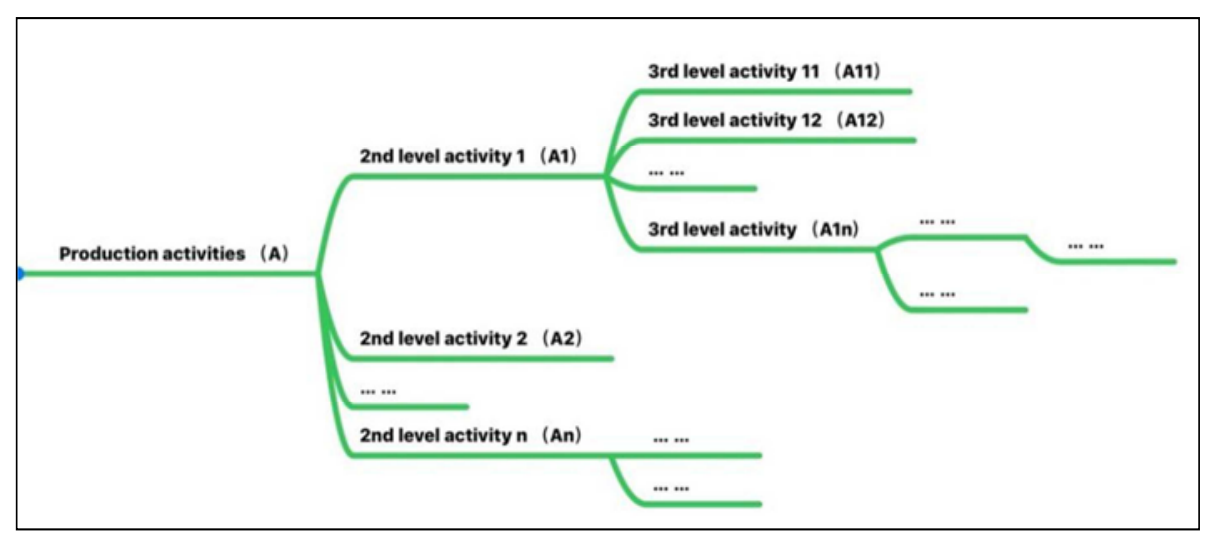

(b)

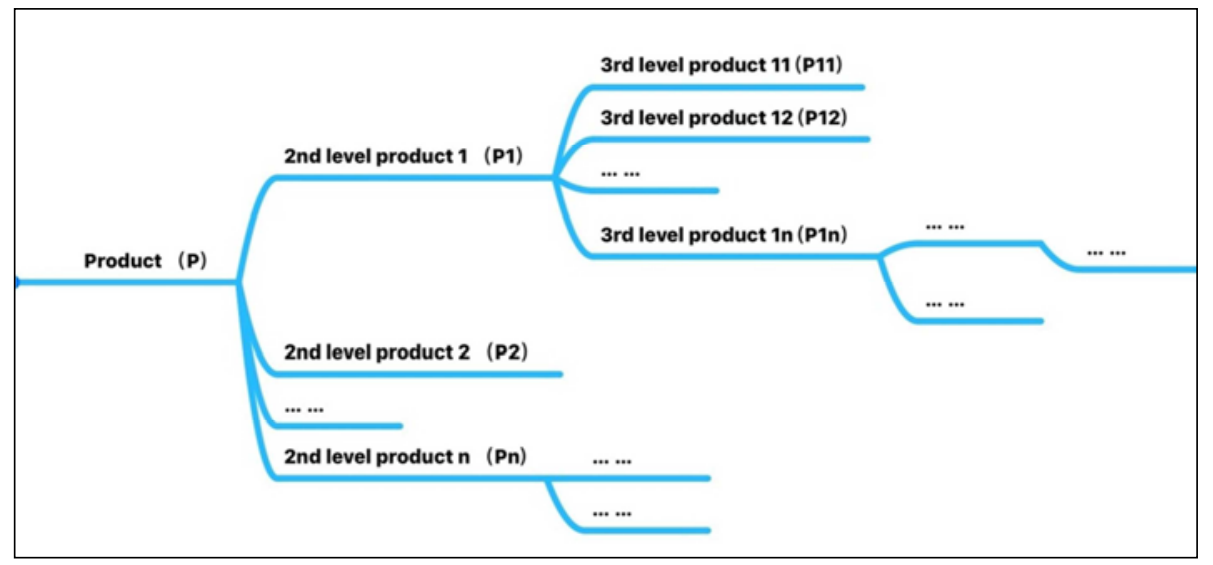

(c)

Figure 2. Production system breakdown structure by organizations (a), activities (b), products (c).

(2) Production System Breakdown Structure of GAS

By decomposing the GAS production system with the three categories of the production organizations, production activities and product types, three sets of GAS production system breakdown structures can be obtained. These three kinds of production sub-systems can be defined as the production organization breakdown structure, the production activity breakdown structure and the products type breakdown structure. Three tree structure diagrams composed of these three kinds of breakdown structures can be obtained (as shown in Figure 2), which is defined as the GAS production breakdown structure (SPBS for short, each branch PBS for short).

Each branch of the diagram represents a production system. If the efficiency of each branch is measured, the SPBS diagrams could clearly show the production efficiency distribution in the overall GAS production system from the perspective of production organizations, production activities and product types.

If $O, P$ and $A$ refers to the production system set of production organizations, product types and activities respectively, then, the SPBS can be expressed by the formula 3-8:

$$
O=\left\{O_{1}, O_{2}, \cdots, O_{n}\right\}
$$

$$
\begin{aligned}
& O_{1}=\left\{o_{11}, o_{12}, \cdots, o_{1 n}\right\} \\
& P=\left\{p_{1}, p_{2}, \cdots, p_{n}\right\} \\
& P_{1}=\left\{p_{11}, p_{12}, \cdots, p_{1 n}\right\} \\
& A=\left\{a_{1}, a_{2}, \cdots, a_{n}\right\} \\
& A_{1}=\left\{a_{11}, a_{12}, \cdots, a_{1 n}\right\}
\end{aligned}
$$

\subsection{Efficiency Breakdown Structure of GAS}

\subsubsection{Organization Efficiency Breakdown Structure}

All the production systems are managed by some inner production organizations in the GAS enterprise. Each of the production organizations can be regarded as a production system, and its efficiency is defined as organization efficiency. All these organizations efficiency compose organization efficiency breakdown structure of GAS enterprise.

The first letter "O" of "Organization" is used to represent the organization efficiency set of the GAS, and the figure added to $\mathrm{O}$ is used to represent the number and the level of the breakdown structure, as shown in Figure 2 (a).

\subsubsection{Activity Efficiency Breakdown Structure}

The shipbuilding products are produced by tens of 
thousands of production activities. Each of the production activities is a production process of getting outputs through a certain amount of inputs; its production efficiency is defined as activity efficiency. Based on the activity breakdown structure system, an activities efficiency breakdown structure system of GAS can be obtained.

The first letter "A" of "Activity" is used to represent the activity efficiency set of GAS, adding numbers after the letter "A" shows different activities number and level in the activity efficiency structure, as shown in Figure 2(b).

\subsubsection{Product Efficiency Breakdown Structure}

Products of GAS include end products and intermediate products. Products manufacturing requires for certain production factors input, and the products itself are the output, therefore, the production process of any ship product can be regarded as a production system, and each product can also be decomposed to various intermediate products as per the production process. This kind of production system efficiency is defined as product efficiency, and correspondingly all kinds of products efficiency of GAS compose the product efficiency breakdown structure.

The first letter "P" of "Product" is used to represent the product efficiency set of GAS, adding numbers after the letter "P" shows different activities number and level in the activity efficiency structure, as shown in Figure 2(c).

\subsection{Relationship of the SPBSs}

It is a triangular relationship of production organizations, production activities, and products as shown in Figure 3. The products consume the production activities; the production organizations provide the production activities and the production organizations produce products. In other words, each product is completed by one or several activities, produced by one or several production organizations; and each production organization can manage one or more kinds of activities, with one or more products produced.

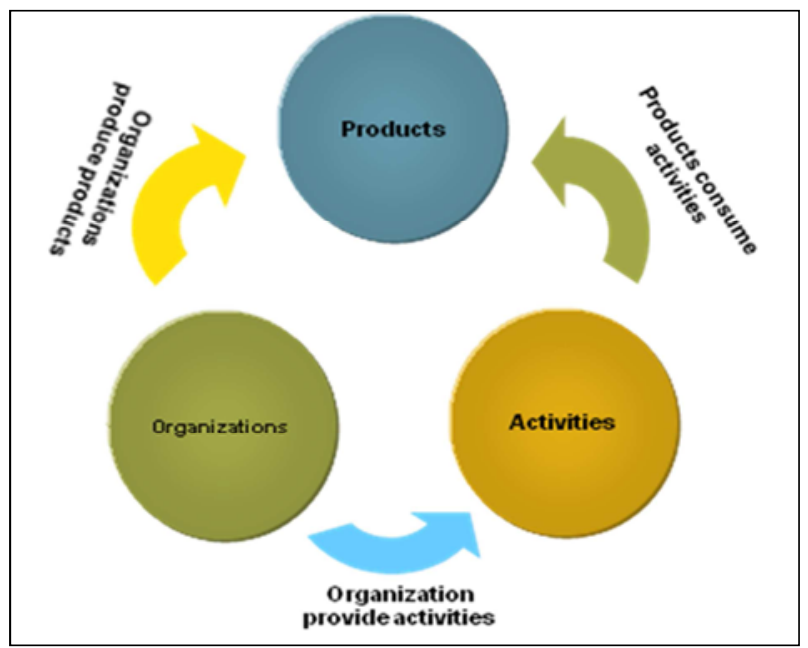

Figure 3. Relationship of Production Organization, Production activity and Products.

Production activity management is the major work of each production organization. All the products are produced by various production activities managed by the production organization. Therefore, the efficiency of these activities are important components of the production organization efficiency, in other words, organization efficiency includes the efficiency of all activities managed by the production organization.

Manufacturing products is the major objective of the production organization. The production efficiency of a production organization is a comprehensive reflection of the product efficiency of all products produced by the production organization. The product is produced by the production organization, so the efficiency of the product depends on the efficiency of the production organization. The activity efficiency and the management efficiency of production organization will be embodied in the product efficiency of production organization.

Because the object of production activities is the products, and the products consume the activities and the activities consume the cost, so the activity efficiency determines the product efficiency. A product is produced by one or more activities, and the product efficiency is an efficiency reflection of all production activities for the product. It is the overall efficiency of all these activities.

\section{Method of Efficiency Evaluation and Measurement}

In order to have a clearly view of the inner efficiency, DEA model, HM TFP (Hicks-Moorsteen TFP Index) model and some of the method currently used will be selected or designed to evaluate the efficiency of each PBS.

\subsection{Mathematical Model of Production Technology and Efficiency}

(1) Production Technology Set

It is the best way to describe the production technology of the GAS by the technology set. The notation $\mathrm{x}$ and $\mathrm{q}$ is used to denote an $N \times l$ input vector of on-negative real numbers and a non-negative $M \times l$ output vector, respectively. (Timothy J Coelli, et al. 2008)The technology set is then defined as:

$$
\mathrm{S}^{t}=\{(\mathrm{x}, \mathrm{q}) \text { : in the period } t \mathrm{x} \text { can produce } \mathrm{q}\}
$$

The production technology defined by the set $\mathbf{S}$, may be equivalently defined using the output set, $\mathrm{P}^{t}(\mathrm{x})$ which represents the set of all output vectors $q$, that can be produced using the input vector $\mathrm{x}$, the output set is defined by

$$
\begin{aligned}
\mathrm{P}^{t}(\mathrm{x}) & =\{(\mathrm{x}, \mathrm{q}): \text { in the period } t \mathrm{x} \text { can produce } \mathrm{q}\} \\
& =\{\mathrm{q}:(\mathrm{x}, \mathrm{q}) \in \mathrm{S}\}
\end{aligned}
$$

The input associated with a given output vector $\mathrm{q}$, is 
defined as the set:

$\mathrm{L}^{t}(\mathrm{q})=\{\mathrm{x}:$ in the period $t \mathrm{x}$ can produce $\mathrm{q}\}=\{\mathrm{x}:(\mathrm{x}, \mathrm{q}) \in \mathrm{S}\}$

The input set consists of all input vectors $\mathbf{x}$, that can produce a given output vector $\mathrm{q}$.

(2) DEA Linear Programming Model

DEA involves the use of linear programming methods to construct a non-parametric piece-wise surface (or frontier) over the data. Efficiency measures are then calculated relative to this surface [24]. Each branch of the shipbuilding production system breakdown structure (PBS) can be taken as a decision-making unit ( $D M U$ ), and the efficiency of the similar PBS or the same PBS at different time can be calculated by DEA method. The ratio of $D M U$ output to input is expressed as

$$
h_{k}=\frac{u_{1} y_{1 k}+u_{2} y_{2 k}+\cdots+u_{q} y_{q k}}{v_{1} x_{1 k}+v_{2} x_{2 k}+\cdots v_{m} x_{m k}}=\frac{\sum_{r=1}^{q} u_{r} y_{r k}}{\sum_{r=1}^{m} v_{i} x_{i k}}
$$

$$
(v \geq 0 ; u \geq 0)
$$

The efficiency value of all $D M U$ using the weights mentioned above are limited to the range of $[0,1]$, namely

$$
\frac{\sum_{r=1}^{q} u_{r} y_{r j}}{\sum_{r=1}^{m} v_{i} x_{i j}} \leq 1
$$

1) An input-oriented CCR linear programming model based on constant returns to scale (CRS) is presented as:

$$
\begin{gathered}
\max \frac{\sum_{r=1}^{q} u_{r} y_{r k}}{\sum_{i=1}^{m} v_{i} x_{i k}} \\
\text { s.t. } \frac{\sum_{r=1}^{q} u_{r} y_{r j}}{\sum_{i=1}^{m} v_{i} x_{i j}} \leq 1 \\
v \geq 0 ; u \geq 0 \\
i=1,2, \cdots, m ; r=1,2, \cdots, q ; j=1,2, \cdots, n
\end{gathered}
$$

2) An output-oriented CCR linear programming model based on constant returns to scale (CRS) is presented as:

$$
\begin{gathered}
\min \sum_{i=1}^{m} v_{i} x_{i k} \\
\text { s.t. } \sum_{r=1}^{s} u_{r} y_{r j}-\sum_{i=1}^{m} v_{i} x_{i j} \leq 0
\end{gathered}
$$

$$
\begin{gathered}
\sum_{r=1}^{q} u_{r} y_{r k}=1 \\
v \geq 0 ; u \geq 0 \\
i=1,2, \cdots, m ; r=1,2, \cdots, q ; j=1,2, \cdots, n
\end{gathered}
$$

3) An input-oriented BCC linear programming model based on variable return to scale (VRS) is presented as:

$$
\begin{gathered}
\min \theta \\
\text { s.t. } \sum_{j=1}^{n} \lambda_{j} x_{i j} \leq \theta x_{i k} \\
\sum_{j=1}^{n} \lambda_{j} y_{i j} \geq y_{i k} \\
\sum_{j=1}^{n} \lambda_{j}=1 \\
\lambda \geq 0 \\
i=1,2, \cdots, m ; r=1,2, \cdots, q ; j=1,2, \cdots, n
\end{gathered}
$$

The dual programming formula of the upper type is:

$$
\begin{gathered}
\max \sum_{r=1}^{s} u_{r} y_{r k}-u_{0} \\
\text { s.t. } \sum_{r=1}^{q} u_{r} y_{r j}-\sum_{i=1}^{m} v_{i} x_{r j}-u 0 \leq 0 \\
\sum_{i=1}^{m} v_{i} x_{i k}=1 \\
v \geq 0 ; u \geq 0 ; u_{0} \text { Free } \\
i=1,2, \cdots, m ; r=1,2, \cdots, q ; j=1,2, \cdots, n
\end{gathered}
$$

4) An output-oriented BCC linear programming model based on variable return to scale (VRS) is presented as:

$$
\begin{gathered}
\min \phi \\
\text { s.t. } \sum_{j=1}^{n} \lambda_{j} x_{i j} \leq x_{i k} \\
\sum_{j=1}^{n} \lambda_{j} y_{i j} \geq \phi y_{i k} \\
\sum_{j=1}^{n} \lambda_{j}=1 \lambda \geq 0 \\
i=1,2, \cdots, m ; r=1,2, \cdots, q ; j=1,2, \cdots, n
\end{gathered}
$$

The dual programming formula of the upper type is: 


$$
\begin{gathered}
\min \sum_{r=1}^{m} v_{i} x_{r k}+v_{0} \\
\text { s.t. } \sum_{r=1}^{q} u_{r} y_{r j}-\sum_{i=1}^{m} v_{i} x_{r j}-v_{0} \leq 0 \\
\sum_{i=1}^{s} u_{r} y_{r k}=1 \\
v \geq 0 ; \quad u \geq 0 ; \quad u_{0} \text { Free } \\
i=1,2, \cdots, m ; r=1,2, \cdots, q ; j=1,2, \cdots, n
\end{gathered}
$$

\subsection{Indicators of Efficiency}

The indicators of efficiency should be selected or designed according to the characters of the PBS, as shown in Table 1.

Table 1. List of Efficiency Indicators of GAS.

\begin{tabular}{lll}
\hline Indicators & Code & Categories \\
\hline Technical Efficiency & $T E$ & $\mathrm{O} / \mathrm{P}$ \\
Scale Efficiency & $S E$ & $\mathrm{O} / \mathrm{P}$ \\
Allocate Efficiency & $A E$ & $\mathrm{O}$ \\
HM TFP Index & $H M T F P$ & $\mathrm{O} / \mathrm{P}$ \\
Technological Change & $T C$ & $\mathrm{O} / \mathrm{P}$ \\
Technical Efficiency Change & $T E C$ & $\mathrm{O} / \mathrm{P}$ \\
Scale Efficiency Change & $S C$ & $\mathrm{O} / \mathrm{P}$ \\
Total Factor Productivity Change & $T F P C$ & $\mathrm{O} / \mathrm{P}$ \\
Labour Productivity & $L P$ & $\mathrm{O} / \mathrm{P} / \mathrm{A}$ \\
Production Speed & $P S$ & $\mathrm{~A}$ \\
Total Factor Productivity & $T F P$ & $\mathrm{O} / \mathrm{P} / \mathrm{A}$ \\
Milestone Period & $M P$ & $\mathrm{P}$ \\
\hline
\end{tabular}

\subsubsection{Indicators of Organization Efficiency}

It is easy to measure the organization efficiency because each branch of the production organization breakdown structure can be taken as an internal enterprise. Like a normal enterprise, the organization efficiency can be measured by DEA and Index method. 4 indicators of technical efficiency are selected, scale efficiency, locative efficiency and HMTFP to describe the level of the production efficiency while select another 4 indicators of technical change, efficiency change, scale efficiency change and TFP change to describe the change of the production efficiency [25-30].

(1) Efficiency Level Indicators

1) Technical efficiency

Technical efficiency reflects the ability of a PBS to obtain maximal output from a given set of inputs. As shown in Figure 4, if a given PBS uses quantities of inputs, defined by the point $\mathrm{P}$, to produce a unit of output, the technical inefficiency of that PBS could be represented by the distance $Q P$, which is the amount by which all inputs could be proportionally reduced without a reduction in output. This is usually expressed in percentage terms by the ratio $Q P / O P$, which represents the percentage by which all inputs need to be reduced to achieve technically efficient production. The technical efficiency (TE) of a PBS is most commonly measured by the ratio which is equal to one minus $Q P / O P$. It takes a value between zero and one, and, hence, provides an indicator of the degree of technical efficiency of the PBS. Avalue of one implies that the PBS is fully technically efficient.

$$
T E=O Q / O P
$$

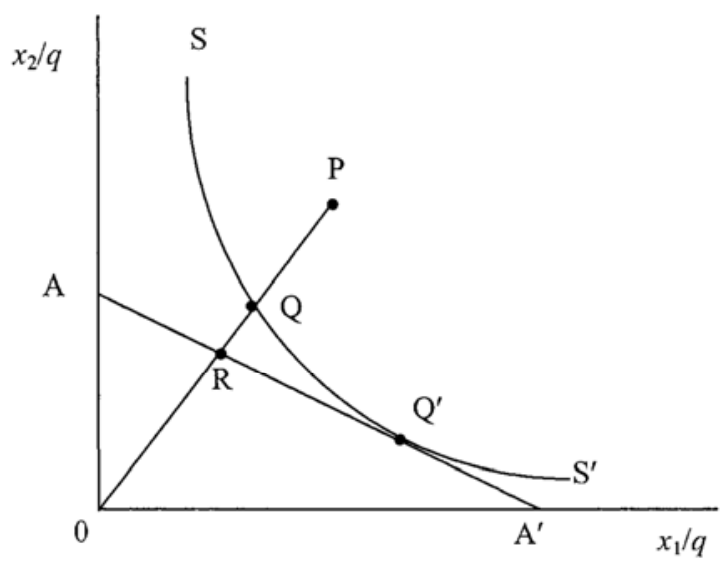

Figure 4. Technical and Allocative Efficiencies.

\section{2) Scale efficiency}

Scale efficiency ( $S E$ ) is the production efficiency when the marginal output of a PBS of a certain GAS is zero. Scale efficiency exists only when production technology is variable return to scale (VRS). In solving scale efficiency, CRS model shall be adopted, that is, assume the PBS is in the CRS state. Under the VRS production technology, the scale efficiency value can be separated by comparing the CRS efficiency value $(T E)$ and the VRS efficiency value ( $P T E)$, whose formula is:

$$
S E=T E / P T E
$$

\section{3) Allocative efficiency}

Allocative efficiency reflects the ability of a PBS to obtain maximal output from a given set of inputs when the inputs prices are taken into consideration. The difference between allocative efficiency and technical efficiency is that the technical efficiency is the ability to use input without considering the price conditions, while allocative efficiency refers to the best combination of input to produce the "optimal" number of products combination. When there is input price information, the allocative efficiency can be obtained by the ratio of cost efficiency to technical efficiency. Cost efficiency can be mathematically programmed by minimizing costs, maximizing revenues, and maximizing profits.

\section{a) Cost minimization}

Under the circumstances of minimizing the cost of VRS, suppose that $\mathrm{w}_{i}^{\prime}$ represents the $i$-th PBS's input price, $N \times l$ vector, $x_{i}^{*}$ represents the $i$-th PBS'S cost minimization vector at a given input price $\mathrm{w}_{i}$ and input amount of output level $\mathrm{q}_{i}$, the cost minimization DEA model is:

$$
\min \lambda, x i * \mathrm{~W}_{i}^{\prime} \mathbf{x}_{i}^{*}
$$




$$
\begin{gathered}
s t-\mathrm{q}_{i}+\mathrm{Q} \lambda \geq 0 \mathrm{x}^{*}{ }^{*}-\mathrm{X} \lambda \geq 0 \\
I 1^{\prime} \lambda=1 \\
\lambda \geq 0
\end{gathered}
$$

The total cost efficiency ( $C E$ ) and allocative efficiency of the $i$ PBS can be expressed as:

$$
C E=\mathrm{w}_{i}^{\prime} \mathrm{x}_{i}^{*} / \mathrm{w}_{i}^{\prime} \mathrm{x}_{i}
$$

b) Revenue maximization

Under the circumstances of minimizing the cost of VRS, suppose that $\mathrm{P}_{i}$ represents the $i$-th PBS's input factor prices $M \times l$ vector, $\mathrm{q}_{i}$ represents the $i$ PBS's revenue maximization vector at a given input price $\mathrm{P}_{i}$ and input amount of output level $\mathrm{x}_{i}$, the revenue maximization DEA model is:

$$
\begin{gathered}
\min \lambda, y i * \mathrm{p}_{i}^{\prime} \mathrm{q}_{i}^{*} \\
s t-\mathrm{q}_{i}^{*}+\mathrm{Q} \lambda \geq 0 \\
\mathrm{x}_{i}-\mathrm{X} \lambda \geq 0 \\
I 1 / \lambda=1 \quad \lambda \geq 0
\end{gathered}
$$

The total revenue efficiency ( $R E$ ) of the $i$-th PBS can be expressed in the following form: $R E$

$$
\begin{aligned}
& R E=\mathrm{p}_{i}^{\prime} \mathrm{q}_{i} / \mathrm{p}_{i}^{\prime} \mathrm{q}^{*}{ }_{i} \\
& A E=R E / T E
\end{aligned}
$$

c) Profit maximization

The profit maximization model of DEA is:

$$
\begin{gathered}
A E=C E / T E \\
\max \lambda, y^{*}, x i^{*}\left(p_{i}^{\prime} q_{i}^{*}-w_{i}^{\prime} w_{i}^{*}\right) \\
s t-\mathrm{q}_{i}^{*}+\mathrm{Q} \lambda \geq 0 \\
\mathbf{x}_{i}^{*}-\mathbf{X} \lambda \geq 0 \\
I 1^{\prime} \lambda=1 \lambda \geq 0
\end{gathered}
$$

4) HM TFP Index

The HM TFP index is used to measure the ratio of the output growth to input growth, and it refers to the output growth as per unit input growth. In view of the price change factors, the growth of output and input is replaced by the output index and the input quantity index, as shown in Formula 28:

$$
\text { HM TFP }=\frac{\text { Output Growth }}{\text { Input Growth }}=\frac{\text { Output Quantity Index }}{\text { Input Quantity Index }}
$$

Suppose $p_{m j}$ and $q_{m j}$ represents the prices and quantities of $m(m=1,2, \cdots, M)$ commodities in the period $j(j=s, t)$, or in the production system. The output and the input price index numbers can be expressed by the Laspeyes price index numbers, Paasche Price index numbers or the Fisher price index numbers:

$$
\text { Laspeyes Price index numbers } P_{s t}^{L}=\frac{\sum_{m=1}^{M} p_{m} q_{m s}}{\sum_{m=1}^{M} p_{m s} q_{m s}}
$$

$$
\text { Paasche Price index numbers } P_{s t}^{P}=\frac{\sum_{m=1}^{M} p_{m} q_{m t}}{\sum_{m=1}^{M} p_{m s} q_{m t}}
$$

Fisher price index numbers $P_{s t}^{F}=\sqrt{P_{s t}^{L} \times P_{s t}^{P}}$

(2) Productivity Changes Indicators

There are four sources of change in productivity, namely technological change, technological efficiency change, scale efficiency change and output mixing effect [24].

1) Technical change

Technological change occurs due to changes in production technology, resulting in the change of the production frontier of the production system or production capacity, and change of the productivity of corresponding production system, with such degree of change expressed as:

$$
\begin{gathered}
T C=\frac{d_{o}^{t}(\mathrm{x}, \mathrm{q})}{d_{o}^{s}(\mathrm{x}, \mathrm{q})} \\
T C_{O}^{s, t}\left(\mathrm{x} s, \mathrm{q}_{s}, \mathrm{x}_{t}, \mathrm{q}_{t}\right)=\left[\frac{d_{o}^{t}\left(\mathrm{x} s, \mathrm{q}_{s}\right)}{d_{o}^{s}\left(\mathrm{x} s, \mathrm{q}_{s}\right)} \times \frac{d_{o}^{t}\left(\mathrm{x}_{t}, \mathrm{q}_{t}\right)}{d_{o}^{s}\left(\mathrm{x}_{t}, \mathrm{q}_{t}\right)}\right]^{0.5}
\end{gathered}
$$

2) Technical efficiency change

The change in technical efficiency refers to the increase in productivity occurred due to the improvement of the available technical capacity of the shipbuilding enterprises, with this change expressed by Formula 34:

$$
T E C_{o}^{s, t}\left(\mathrm{x}_{s}, \mathrm{q}_{s}, \mathrm{x}_{t}, \mathrm{q}_{t}\right)=\frac{d_{o}^{t}\left(\mathrm{x} t, \mathrm{q}_{t}\right)}{d_{o}^{s}\left(\mathrm{x} s, \mathrm{q}_{s}\right)}
$$

3) Scale efficiency change

The change in scale efficiency refers to the degree of movement of operation towards the optimal scale of technology occurred due to improvement of operation scale of shipbuilding enterprises.

$$
\begin{gathered}
S E_{o}^{t}(\mathrm{x}, \mathrm{q})=\frac{T E_{t}^{*}(\mathrm{x}, \mathrm{q})}{T E_{t}(\mathrm{x}, \mathrm{q})}=\frac{d_{o}^{* t}(\mathrm{x}, \mathrm{q})}{d_{o}^{t}(\mathrm{x}, \mathrm{q})} \\
S E_{o}^{t}\left(\mathrm{x}_{s}, \mathrm{x}_{t}, \mathrm{q}\right)=\frac{S E_{o}^{t}(\mathrm{x} t, \mathrm{q})}{S E_{o}^{t}(\mathrm{x} s, \mathrm{q})} \\
S E C_{o}^{s, t}\left(\mathrm{x}_{s}, \mathrm{x}_{t}, \mathrm{q}_{s}, \mathrm{q}_{t}\right)=\left[S E C_{o}^{s}\left(\mathrm{x} s, \mathrm{x} t, \mathrm{q}_{s}\right) \times S E C_{o}^{t}\left(\mathrm{x}_{s}, \mathrm{x}_{t}, \mathrm{q}_{s}\right)\right]^{0.5}
\end{gathered}
$$

4) Change of total factor productivity

The change of total factor productivity is the product of sources of change in productivity and a comprehensive 
reflection of the four sources of productivity change [24], which can be expressed by Formula 38 :

TFP change $=$ technical change $\times$ technical efficiency change $\times$ scale efficiency change $\times$ output mixing effect

$$
\begin{aligned}
\operatorname{TFPC}^{s, t}(\mathrm{x} s, & \left.\mathrm{x}_{t}, \mathrm{q}_{s}, \mathrm{q}_{t}\right)=\left[\frac{d_{o}^{t}\left(\mathrm{x}_{s}, \mathrm{q}_{s}\right)}{d_{o}^{s}\left(\mathrm{x}_{s}, \mathrm{q}_{s}\right)} \times \frac{d_{o}^{t}\left(\mathrm{x}_{t}, \mathrm{q}_{t}\right)}{d_{o}^{s}\left(\mathrm{x} t, \mathrm{q}_{t}\right)}\right]^{0.5} \times \frac{d_{o}^{t}\left(\mathrm{x}_{t}, \mathrm{q}_{t}\right)}{d_{o}^{s}\left(\mathrm{x}_{s}, \mathrm{q}_{s}\right)} \\
\times & {\left[S E C_{o}^{s}\left(\mathrm{x}_{s}, \mathrm{x}_{t}, \mathrm{q}_{s}\right) \times S E C_{o}^{t}\left(\mathrm{x} s, \mathrm{x}_{t}, \mathrm{q}_{s}\right)\right]^{0.5} } \\
\times & \left.\times O M E^{s}\left(\mathrm{x}_{s}, \mathrm{q}_{s}, \mathrm{q}_{t}\right) \times O M E^{t}\left(\mathrm{x}_{t}, \mathrm{q}_{s}, \mathrm{q}_{t}\right)\right]^{0.5}
\end{aligned}
$$

Wherein, the fourth source of productivity change is the mixing efficiency shown in Formulas 39 and 40:

$$
\begin{gathered}
O M E^{t}\left(\mathrm{x}, \mathrm{q}_{s}, \mathrm{q}_{t}\right)=\frac{S E_{o}^{t}\left(\mathrm{x}, \mathrm{q}_{t}\right)}{S E_{o}^{t}\left(\mathrm{x}, \mathrm{q}_{s}\right)} \\
O M E^{s, t}\left(\mathrm{x}_{s}, \mathrm{x}_{t}, \mathrm{q}_{s}, \mathrm{q}_{t}\right)=\left[O M E^{s}\left(\mathrm{x}_{s}, \mathrm{q}_{s}, \mathrm{q}_{t}\right) \times O M E^{t}\left(\mathrm{x}_{t}, \mathrm{q}_{\mathrm{q}}, \mathrm{q}_{t}\right)\right]^{0.5} \\
=\left[\frac{S E_{o}^{s}\left(\mathrm{x} s, \mathrm{q}_{t}\right)}{S E_{o}^{s}\left(\mathrm{x} s, \mathrm{q}_{s}\right)} \times \frac{S E_{o}^{t}\left(\mathrm{x}_{t}, \mathrm{q}_{t}\right)}{S E_{o}^{t}\left(\mathrm{x}_{t}, \mathrm{q} s\right)}\right]^{0.5}
\end{gathered}
$$

\subsubsection{Indicators of Activity Efficiency}

The activity efficiency level can be described by productivity since each of activity PBS branches can be regarded as a "machine". As activities are generally done by people and machine, activity efficiency also can be expressed in terms of labor productivity. The production capability of the machine generally remains unchanged, and the efficiency is mainly determined by the operator's ability. Therefore the labor productivity and production speed are the best indicators to measure the efficiency of activity.

(1) Labor productivity

The labor productivity refers to the ratio of the output and labor input of the GAS, reflecting utilization degree of the labor resources by GAS [31]. The input of labor productivity is expressed in terms of working hours $(L)$, the output is usually expressed by $C G T$, and the Formula is as follows:

$$
S F P=\frac{P^{t}\left(\mathrm{x}_{t}\right)-P^{s}\left(\mathrm{x}_{s}\right)}{L^{t}\left(\mathrm{x}_{t}\right)-L^{s}\left(\mathrm{x}_{s}\right)}
$$

(2) Production speed

Production speed refers to the output per unit time. Production speed is not a direct indicator of efficiency, because this indicator only reflects the relationship between output and time, rather than the relationship between output and input. But in the case of constant or little change in input, this indicator can be compared as a relative efficiency.

Production speed can be expressed in terms of output per unit time, If $v$ is used to represent the production speed, $P$ the output produced in time $t$, and the production speed formula is:

$$
v=\frac{P}{t}
$$

\subsubsection{Indicators of Product Efficiency}

(1) Total factor productivity (TFP)

The product efficiency of the GAS is the input consumed by the unit product, so TFP is the most suitable indicator to evaluate it. It is the reciprocal relationship with the input consumed by the unit product.

The total factor productivity refers to the ratio of output of the GAS to all production factors, reflecting the utilization of all factors by the assembly shipbuilding. Assume $L^{s}(\mathrm{x})$, $L^{t}(\mathrm{x}), P^{s}(\mathrm{x})$ and $P^{t}(\mathrm{x})$ respectively represent the inputs and outputs for the period from $\mathrm{s}$ to $t$ time, the total factor productivity can be expressed by Formula 43:

$$
T F P=\frac{P^{t}(\mathbf{x})-P^{s}(\mathbf{x})}{L^{t}(\mathbf{x})-L^{t}(\mathbf{x})}
$$

The output index of total factor productivity can be expressed by the compensated gross tonnage $(C G T)$. Due to the diversification of its production factors, the input index shall be expressed by a certain summing process.

(2) Milestone period

The product efficiency of GAS can be described by milestones. Milestones are key tasks or events in shipbuilding. The time interval between two milestones is often referred to as the milestone period. The building period of each ship's product is typically indicated by milestones. The production input of GAS usually fluctuates in S curve with the milestone time. Milestone interval will determine the total amount of input, while the product efficiency means the total input per product. As a result, milestones periods can be used as an indicator of the product efficiency.

In the GAS, there are generally 14 shipbuilding milestones, of which the contract signing, steel cutting, keel laying, launching and delivery are the most important milestones. The interval time between these five milestones can serve as product efficiency indicators for product PBS.

\subsection{Input and Output Variables}

\subsubsection{Output Variables}

The total output of the GAS is divided into two categories: end output and intermediate output. The end output refers to the final output of the GAS enterprises. The intermediate output refers to intermediate products produced in the production process of GAS. These intermediate products continue are the input of the next working stage.

(1) End Output variables

The end outputs of the GAS enterprise generally include three major categories of products, namely, marine engineering products, offshore products and heavy industry products. These three categories of products can be subdivided by types further. Usually, the output amount of end output is measured by the number of annual products, deadweight ton, gross tonnage, and compensated gross tonnage (CGT).

(2) Intermediate Output variables

If every construction stage within the shipbuilding enterprise is regarded as an "internal enterprise", therefore, each intermediate product produced in the construction stage can be 
regarded as the "internal business" output. The intermediate products of the GAS can be divided into five categories: raw materials, parts, groups, small assemblies and blocks. They are the products divided from the GAS work breakdown structure.

The intermediate product can be measured by some physical or technical characteristics as shown in Table 2. There are also some features showing the differences of intermediate products, which can be used as correction coefficients for the amount of work, such as spatial, tolerance, welding equipment, welding method, shape, weight, material coefficients etc. The values of these correction coefficients are closely related to the shipbuilding facilities, methods and technologies. The output of intermediate products could be calculated by Formula 44 .

$$
P_{c}=I \times \alpha_{1} \times \alpha_{2} \times, \cdots, \times \alpha_{n}
$$

Wherein, $P_{c}$ refers to the output after processing, $I$ refers to the compensate factor, $\alpha_{1}, \alpha_{2}, \ldots \alpha_{n}$ are the correction coefficient. $I$

Table 2. Output Variables of Intermediate Products.

\begin{tabular}{|c|c|c|c|}
\hline Job tasks & Job object & Technical Characteristic & Measuring unit of output \\
\hline Surface pretreatment & Steel sheet & Weight, geometric dimension & Processing area \\
\hline Cutting & Steel plate, section & Weight, geometric dimension, tolerance, mounting position & Weight \\
\hline Welding & Welding seam & $\begin{array}{l}\text { Welding geometric dimension, welding type, space position, } \\
\text { welding method }\end{array}$ & Welding volume \\
\hline Assembly & $\begin{array}{l}\text { parts, Small assembly, } \\
\text { Blocks, Hull }\end{array}$ & Weight, geometric dimension, mounting position, tolerance & Weight \\
\hline Painting & Surface & $\begin{array}{l}\text { Geometric dimension: coating type, location, coating } \\
\text { method, thickness, }\end{array}$ & Surface area \\
\hline
\end{tabular}

\subsubsection{Input Variables}

The production inputs are generally divided into three categories, namely, materials, land and labor. The production input of GAS on this basis can be further broken down into five categories, namely, human resources, facilities, materials, energy and services purchased. The production input and measurement methods of the common GAS enterprises are shown in Table 3.

Table 3. Input Variables.

\begin{tabular}{lll}
\hline Input factors & Characteristics of technical & Input variables \\
\hline Labor force & quantities, skills & Ability, working hours \\
Equipment and tools & quantities, ability & Ability, service time \\
Construction site & quantities, space, ability & Unit area (or volume) \\
Tooling facilities & quantities, pieces, ability & Ability, service time \\
Lifting equipment & quantities, ability & Ability, service time \\
Transportation equipment & quantities, ability & Ability, service time \\
Energy & $\mathrm{KW}, \mathrm{M}^{3}$ & Dosage \\
Materials & Quantities, weight & Quantity, weight \\
\hline
\end{tabular}

\section{Empirical Application}

Now the PBS and the efficiency measurement methods can be integrated into a model to measure the efficiency of a GAS production system. In order to have a clear view of this model, three simple models are made to illustrate how to apply this method on the organization efficiency, product efficiency and activity efficiency separately.

(1) Firm Efficiency

The 13 Chinese GSA enterprises are taken to construct a simple PBS of production organizations, select TE, SE, TC, TEC, SEC, and TPFC as the efficiency indicator, take the delivered vessels' quantities and $C G T$ as two output variables and take the quantities and areas of docks, quantities and capacities of lifting facilities as four input variables. All the input and output data are from the Yearbook of Chinese Shipbuilding Industry. The measurement results in Table 4 show that China's shipbuilding industry is in DRS from the year 2009-2014, which may be related to state-owned enterprises are in DRS, while state-owned enterprises' output is relatively large in china. Other conclusions are also basically consistent with the evaluation results of counterparts.

(2) Organization Efficiency

Five production departments of two shipyards are taken to construct a simple PBS of production organizations. In this PBS, each shipyard is divided into block department and assembly department. The blocks and the erected blocks are taken as the output variables, take the quantities and areas of docks, quantities and capacities of lifting facilities as four input variables, select TE, SE, TC, TEC, SEC, and TPFC as the efficiency indicator, take the data from the production records of DSIC in the year 2013-2014. The measurement results in Table 4 show that the two shipyards in scale efficiency and technical efficiency.

(3) Activity Efficiency

The erection work is taken to construct a simple PBS of production activities. In this PBS, the erection work is decomposed into 2 categories and 7 sub-categories as shown in Table 5. The production speed is taken as the efficiency indicator, and the data is taken from the production records of DSIC in the year 2013-2014. The results in Table 5 show progress of the activity efficiency with the passage of time clearly. 
Table 4. Firm Efficiency and Organization Efficiency.

\begin{tabular}{|c|c|c|c|c|c|c|c|c|}
\hline Enterprises/Organizations & Code & $T E$ & $S E$ & ROS & $T C$ & $T E C$ & $S E C$ & TFPC \\
\hline Nationwide & $O$ & 1.000 & 0.597 & DRS & 1.029 & 0.920 & 1.029 & 0.947 \\
\hline State owned enterprises & $O 1$ & 0.950 & 0.569 & DRS & 1.059 & 0.977 & 1.049 & 1.035 \\
\hline Private enterprises & $O 2$ & 1.000 & 0.748 & DRS & 0.958 & 0.862 & 1.003 & 0.827 \\
\hline Joint venture enterprise & O3 & 1.000 & 0.949 & DRS & 1.010 & 1.053 & 1.010 & 1.064 \\
\hline CSSC & 011 & 1.000 & 0.732 & DRS & 1.053 & 0.943 & 1.053 & 0.993 \\
\hline CSIC & 012 & 1.000 & 0.521 & DRS & 1.017 & 0.918 & 1.081 & 0.933 \\
\hline DSIC & 0111 & 0.881 & 0.881 & DRS & 1.024 & 0.982 & 1.003 & 1.006 \\
\hline SWS & 0121 & 1.000 & 1.000 & - & 1.000 & 0.977 & 1.000 & 0.977 \\
\hline $\mathrm{HZ}$ & 0122 & 0.680 & 0.863 & IRS & 1.093 & 0.942 & 1.014 & 1.029 \\
\hline BS & 0112 & 0.500 & 0.862 & IRS & 1.074 & 0.975 & 1.009 & 1.047 \\
\hline GSI & O123 & 0.721 & 0.613 & IRS & 1.178 & 0.875 & 1.103 & 1.031 \\
\hline BSIC & 0113 & 0.667 & 0.087 & IRS & 1.512 & 0.945 & 1.458 & 1.428 \\
\hline GSIC & 0114 & 0.670 & 0.407 & IRS & 1.269 & 0.807 & 1.189 & 1.024 \\
\hline NACKS & 031 & 1.000 & 0.949 & IRS & 1.010 & 1.039 & 1.010 & 1.050 \\
\hline NTS & 021 & 1.000 & 1.000 & - & 0.755 & 0.873 & 0.804 & 0.659 \\
\hline YS & O22 & 1.000 & 1.000 & - & 1.000 & 0.775 & 1.000 & 0.775 \\
\hline RS & O23 & 0.511 & 0.536 & IRS & 1.078 & 0.950 & 1.040 & 1.024 \\
\hline JHS & O24 & 1.000 & 0.511 & IRS & 1.094 & 0.835 & 1.094 & 0.913 \\
\hline DYS & 025 & 1.000 & 1.000 & - & 1.000 & 0.822 & 1.000 & 0.822 \\
\hline Block Dep.1 & $O 1$ & 1.000 & 1.000 & - & 0.960 & 1.000 & 0.998 & 0.957 \\
\hline Block Dep.2 & $O 2$ & 1.000 & 0.877 & IRS & 1.006 & 1.000 & 0.993 & 0.998 \\
\hline Slipway Assembly Dep.1 & $O 2$ & 1.000 & 1.000 & - & 1.000 & 0.812 & 1.000 & 0.965 \\
\hline Slipway Assembly Dep. 2 & O4 & 1.000 & 0.763 & IRS & 0.987 & 1.021 & 1.000 & 0.990 \\
\hline Dock Assembly Dep.1 & O5 & 1.000 & 1.000 & - & 1.000 & 1.307 & 1.000 & 0.952 \\
\hline Dock Assembly Dep. 2 & O6 & 1.000 & 1.000 & - & 1.000 & 1.307 & 1.000 & 0.908 \\
\hline Dock Assembly Dep.3 & O7 & 1.000 & 1.000 & - & 1.000 & 1.335 & 1.000 & 1.090 \\
\hline
\end{tabular}

Table 5. The activity efficiency of erection.

\begin{tabular}{|c|c|c|c|c|}
\hline Activity & Code & 2014 & 2015 & 2016 \\
\hline Pre-erection & $A 1$ & 3.8 & 4.6 & 4.5 \\
\hline erection & $A 2$ & 8.4 & 8.5 & 7.6 \\
\hline Bow Pre-erection & $A 11$ & 4.9 & 4.9 & 5.3 \\
\hline Engine room Pre-erection & $A 12$ & 4.1 & 4.0 & 3.8 \\
\hline Stern Pre-erection & $A 13$ & 3.8 & 4.4 & 4.2 \\
\hline Deck Pre-erection & $A 14$ & - & 2.7 & 3.7 \\
\hline Bottom Pre-erection & $A 15$ & 2.5 & 6.3 & 2.5 \\
\hline Bilge Pre-erection & A16 & 4.3 & 4.9 & 5.7 \\
\hline Bulkhead Pre-erection & $A 17$ & 2.5 & 3.6 & 6.1 \\
\hline Bow erection & $A 21$ & 8.3 & 12.9 & 11.9 \\
\hline Engine room erection & $A 22$ & 9.8 & 10.0 & 13.5 \\
\hline Bilge erection & $A 23$ & 9.9 & 8.3 & 13.5 \\
\hline Deck erection & $A 24$ & - & 8.1 & 7.9 \\
\hline Bottom erection & $A 25$ & 5.9 & 6.7 & 5.2 \\
\hline Bilge erection & $A 26$ & 9.6 & 8.7 & 6.5 \\
\hline Bulkhead erection & $A 27$ & 7.4 & 7.0 & 6.0 \\
\hline
\end{tabular}

(4) Product Efficiency

The container ships, oil tankers and bulk cargo carriers produced by DSIC are taken to construct a simple PBS of product efficiency. In this PBS, the products are decomposed in to 3 levels as shown in Table 5. The milestone period of SC-KL, KL-ST, KL-LC, ST-ST AND ST-DL (total 6 milestones) are selected as the efficiency indicators, and take the date from the production records DSIC in the year of 2011-2016. The efficiency measurements results in Table 6 show the differences between different products and the changes of productivity of one certain product, which can provide the basis of product planning combination with the aim to improve the production efficiency. 
Table 6. Product Efficiency of a Shipyard.

\begin{tabular}{|c|c|c|c|c|c|c|}
\hline Product & Code & SC-KL & KL-ST & KL-LC & ST-ST & ST-DL \\
\hline Container vessels & $P 1$ & 176 & 66 & 130 & 126 & 34 \\
\hline Tanker & $P 2$ & 164 & 55 & 132 & 100 & 47 \\
\hline Bulk cargo carrier & P3 & 176 & 64 & 153 & 108 & 53 \\
\hline Product oil tanker & $P 22$ & 151 & 39 & 110 & 84 & 51 \\
\hline Chemical tanker & $P 23$ & 159 & 74 & 210 & 124 & 39 \\
\hline $1800 \mathrm{TEU}$ & $P 17$ & 147 & 33 & 97 & 86 & 21 \\
\hline 3900TEU & P15 & 170 & 71 & 117 & 137 & 22 \\
\hline 6600TEU & P14 & 179 & 43 & 118 & 94 & 29 \\
\hline 8800TEU & P13 & 213 & 85 & 141 & 146 & 32 \\
\hline 9250TEU & P12 & 175 & 90 & 171 & 148 & 82 \\
\hline $10 \mathrm{KTEU}$ & P11 & 185 & 79 & 117 & 133 & 28 \\
\hline VLOC & P31 & 209 & 66 & 131 & 107 & 50 \\
\hline BC18K & P32 & 162 & 63 & 93 & 108 & 46 \\
\hline BC810 & P33 & 158 & 64 & 236 & 110 & 63 \\
\hline PC1100 & P221 & 143 & 41 & 110 & 85 & 68 \\
\hline PC760 & P222 & 159 & 36 & 109 & 82 & 37 \\
\hline
\end{tabular}

\section{Conclusions}

The efficiency of the GAS production system is comprehensively affected by the managing, technical activities and product mix. The causes of inefficiency are hidden somewhere inside of the GSA production system. From these points of view, the GAS production is decomposed into a production system breakdown structures, and a set of efficiency measurement methods with the efficiency indicators are designed. The Efficiency Measurement Model of GAS is developed based on the production system breakdown structures and the corresponding measuring methods. By this model, the shipbuilding efficiency is measured by the firm efficiency and the breakdown efficiency. The breakdown efficiency is consists of organization efficiency, activity efficiency and product efficiency reflecting the efficiency level or the productivity changes all over the GSA production system. The empirical application shows that this model is a suitable approach to analyze the efficiency of GAS. The measurement results obtained by this model can comprehensively reflect the levels of production efficiency of GAS; disclose the exact places and the causes of inefficiency, help finding the proper measures to improve production efficiency.

\section{References}

[1] Xu Miaomiao. 2017., Shipbuilding's battle in cutting overcapacity. China ship survey, (2):11-14+108-109.

[2] Li yan and He Canfei., 2014. Research progress in manufacturing industry productivity. Process in Geography, 33(3):390-410.

[3] Tan Song and Cao Bo., 2016. How to lean from Japan and South Korea ship enterprise experience during the transformation of Chinese ship enterprises under "bear market 2.0". China ship survey, (11):84-89.
[4] Zhang Minghua., 2005. The study on lean shipbuilding system. Harbin Engineering University, 13-27.

[5] Chen Qiang., 2001. Center shipbuilding model study and application. Haerbin Engineering University, 44-90.

[6] Yu Fengping., 2010. Research on General Assembly Shipbuilding mode. Dalian university of technology, 30-115.

[7] Manlis N. Kritikos., 2017. A full ranking methodology in data envelopment analysis based on a set of dummy decision making units. Expert system with applications, (77):211-225.

[8] Lei Chen, Ying-Ming Wang and Fujun Lai., 2017. Semidisposability of undesirable outputs in data envelopment analysis for environmental assessments. European journal of operational research, 260:655-664.

[9] Jianfeng Ma, Linan Qi and Lizhi Deng., 2017. Efficiency measurement and decomposition in hybrid two-stage DEA with additional inputs. Expert system with applications, 79:348-357.

[10] Chen C M and Zhu J., 2011. Efficient resource allocation via efficiency bootstraps: An application to $R \& D$ project budgeting. Operations Research, 59(3):729-741.

[11] Vincent Charles and Fabien Cornillier., 2017. Value of the stochastic efficiency in data envelopment analysis. Expert system with applications, (81):349-357.

[12] David Blazek and Robin C. Sickles., 2010. The impact of knowledge accumulation and geographical spillovers on productivity and efficiency: The case of U.S. shipbuilding during WW II . Economic modeling, 1484-1497.

[13] Zhang hao and $\mathrm{Xu}$ Xuanguo. Analysis and evaluation on management efficiency of shipbuilding enterprises based on the DEA. Journal of Systems \& Management, 2007, 21(4):91-94.

[14] Yue Na., 2011. The research of technical efficiency of China's shipbuilding Enterprises based on DEA. Dalian maritime university: 18-31.

[15] Chen Yong, Su Kun and Tao Yonghong., 2011. Empirical research on shipping industrial efficiency in the Yangtze River delta region with Data Envelopment Analysis Method. Shipbuilding of China, 52(4):246-252. 
[16] Zhang Li, Xu Zhicheng and Liu Yiqing., 2011. Study on the production process optimization of small and medium shipyards based on the DEA method. Ship \& ocean engineering, 40(3):73-76.

[17] Ge Yongda and Zhang Hao, Su Xiang., 2012. Analysis of the Working Team Activity Responsibility cost for shipbuilding enterprise based on the DEA. Ship engineering, 34(2):70-73.

[18] Jung-sun LEE., 2013. Directions for the Sustainable Development of Korean Small and Medium Sized Shipyards. The Asian journal of shipping and logistics, 29 (3):335-360.

[19] Jing Wei and Jing Xuehuai., 2014. Assessment on Chinese shipping industrial efficiency based on super-efficiency DEA. Ship \& boat, 5:49-55.

[20] Jaehun Park, Dongha Lee and Joe Zhu., 2014. An integrated approach for ship block manufacturing process performance evaluation: Case form a Korean shipbuilding. International journal production Economics, (156):214-222.

[21] Tao Yonghong, Zou jia and Su Kun., 2013. Shipbuilding performance based on the Sto NED methods within China, Korea and Japan. Journal of Jiangsu University of science and technology (Natural science edition), (01):86-93.

[22] Zhou Chengyin, Huang Longlong and Xie Xin., 2014. Research of China shipbuilding development index. Shipbuilding technology, 132(7):8-10.

[23] Qu Yuge., 2014. The productivity growth and convergence analysis on shipbuilding industry in China. Journal of Hebei University of economics and business, 35(3):116-120.

[24] Timothy J Coelli, D S Prasada Rao, Christopher J. O Donnell and George E, Wang Zhongyu (translate)., 2008. An introduction to efficiency and productivity analysis. Beijing: Chinese Renmin University press, (2):72-80.

[25] Bi Gongbing, Liang Liang and Yang Feng., 2010. DEAefficiency evaluation model for simple network production. Systems Engineering-Theory \& Practice, 30(3):496-500.

[26] Liu Xisong and Li Yue., 2004. Application of activity-based costing in enterprise of our country. Logistics SCI TECH, 113(28):98-101.

[27] Liu Huajun and Yang Qian., 2014. The Spatial Disparities and Influence Factors of China's Total Factor Productivity Growth under the Constraints of resource and Environment. Journal of Management Science, 27(5), 133-144.

[28] Myung-IiRoh and Kyu-Yeul Lee., 2010. Optimal scheduling of block listing in consideration of the minimization of traveling distance while unloaded and wire and shackle replacement of a gantry crane. Journal of marine science technology, (15):190-200.

[29] Seung-kyung Lee, Bongseok Kim, Minhoe Huh, Sungzoon Cho, Sungkyu Park and Daehyung Lee., 2013. Mining transportation logs for understanding the after-assembly block manufacturing process in the shipbuilding industry. Expert systems with applications, 40:83-95.

[30] Zhang Jiachun., 2006. Study of shipbuilding cost Accounting $\&$ cost controlling based on the interim Productions. Nanjing: Nanjing university of Aeronautics and Astronautics, 21-50.

[31] Yuan Peng., 2008. Evolvements of the Regional Disparity in Labor Productivity of Chinese Manufacturing. Journal of Management Science, 21(2), 94-104. 